\title{
Effet De La Combinaison Régénération Naturelle Assistée (RNA) Et Microdose D'engrais Sur La Production Du Mil (Pennisetum Glaucum (L.) R.Br) Dans Les Zones Agro-Écologiques Du Centre-Sud Du Niger
}

\author{
Zounon Christian Serge Félix, \\ Abasse Amadou Tougiani, \\ Massaoudou Moussa,
}

Département de Gestion des Ressources Naturelles (DGRN), Institut National de la Recherche Agronomique du Niger (INRAN), Maradi, Niger Habou Rabiou,

Département de Productions Végétales, Faculté des Sciences Agronomiques, Université de Diffa, Niger, Diffa, Niger

Bado Vincent,

International Crops Research Institute for Semi-Arid Tropics (ICRISAT), Niamey, Niger

Didier Tidjani, Ambouta Karimou,

Département Sciences du sol, Faculté d'Agronomie, Université Abdou Moumouni de Niamey/Niger

\section{Résumé}

Cette étude vise à identifier la microdose optimale d'engrais dans les champs de production du mil, où des pratiques de la régénération naturelle assistée (RNA) sont déjà réalisées. L'expérimentation a été conduite dans 26 villages pratiquant la RNA, dont 10 villages dans la zone sahélienne stricte, 10 villages dans la zone sahélo-soudanienne et 6 villages dans la zone nordsoudanienne du centre-sud du Niger. Un dispositif en bloc randomisé est installé dans chaque village comportant 5 traitements (RNA; RNA + Fumure organique $(\mathrm{F}) ; \mathrm{RNA}+\mathrm{F}+\mathrm{NPK} ; \mathrm{RNA}+$ Phosphate naturel de Tahoua $(\mathrm{PNT})+$ $\mathrm{F}$; RNA+PNT) et un témoin suivant les quatre points cardinaux. Les paramètres mesurés sont : la croissance en hauteur, le nombre de talles, les rendements en grains et en paille de mil. Les résultats ont montré que la hauteur moyenne la plus élevée des plants est obtenue pour le traitement 
RNA+PNT dans la zone sahélienne stricte $(283,9 \pm 86,2 \mathrm{~cm})$ et le nombre élevé de talles moyens pour le témoin de la zone nord-soudanienne $(10,04 \pm 3,1)$. Dans toutes les zones, le traitement RNA+F+NPK a permis d'obtenir les plus grands rendements moyens en grains et en paille de mil. La zone sahélosoudanienne obtient les rendements moyens en grains $(464,1 \pm 213,9 \mathrm{~kg} / \mathrm{ha})$ et en paille $(2126 \pm 1193 \mathrm{~kg} / \mathrm{ha})$ de mil les plus élevés pour le traitement $\mathrm{RNA}+\mathrm{F}+\mathrm{NPK}$. Par contre, les rendements les plus faibles des témoins sont obtenus dans la zone sahélienne stricte, avec 133,3 $\pm 122,7 \mathrm{~kg} / \mathrm{ha}$ pour les grains et $238,5 \pm 238,2 \mathrm{ka} / \mathrm{ha}$ pour la paille. Ces résultats peuvent être utilisés dans le cadre de l'optimisation de la production du mil dans les agrosystèmes au Niger.

Mots clés : Régénération Naturelle Assistée, Fumure Organique, Engrais Minéral, Microdose, Combinaison, Productivité Du Mil, Niger 


\title{
Effect of The Farmer Managed Natural Regeneration (FMNR) and Fertilizer Microdose Combination on The Production of Millet (Pennisetum Glaucum (L.) R.Br) in Agro-Ecological Zones of South Central Niger
}

\author{
Zounon Christian Serge Félix, \\ Abasse Amadou Tougiani, \\ Massaoudou Moussa,
}

Département de Gestion des Ressources Naturelles (DGRN), Institut National de la Recherche Agronomique du Niger (INRAN), Maradi, Niger Habou Rabiou,

Département de Productions Végétales, Faculté des Sciences Agronomiques, Université de Diffa, Niger, Diffa, Niger

Bado Vincent,

International Crops Research Institute for Semi-Arid Tropics (ICRISAT),

Niamey, Niger

Didier Tidjani, Ambouta Karimou,

Département Sciences du sol, Faculté d'Agronomie, Université Abdou Moumouni de Niamey/Niger

\begin{abstract}
This study aims to identify the optimal microdose of fertilizer in millet production fields, where Farmer Managed Natural Regeneration (FMNR) practices are already carried out. The experiment was carried out in 26 villages practicing RNA, including 10 villages in the strict Sahelian zone, 10 villages in the Sahelo-Sudanian zone and 6 villages in the north-Sudanian zone of south-central Niger. A randomized block device is installed in each village comprising 5 treatments (RNA; RNA + Organic manure (F); RNA + F + NPK; RNA + Natural Phosphate of Tahoua (PNT) + F; RNA + PNT) and a next control the four cardinal points. The parameters measured are: height growth, number of tillers, grain and millet straw yields. The results showed that the highest average height of the plants is obtained for the RNA + PNT treatment in the strict Sahelian zone $(283.9 \pm 86.2 \mathrm{~cm})$ and the high number of average tillers for the control in the northern zone. -Sudanian (10.04 \pm 3.1$)$. In all areas,
\end{abstract}


RNA $+\mathrm{F}+\mathrm{NPK}$ treatment resulted in the highest average grain and millet straw yields. The Sahelo-Sudanian zone obtains the highest average grain $(464.1 \pm 213.9 \mathrm{~kg} / \mathrm{ha})$ and straw $(2126 \pm 1193 \mathrm{~kg} / \mathrm{ha})$ millet yields for the RNA + F + NPK treatment. On the other hand, the lowest yields of the controls are obtained in the strict Sahelian zone, with $133.3 \pm 122.7 \mathrm{~kg} /$ ha for the grains and $238.5 \pm 238.2 \mathrm{ka} / \mathrm{ha}$ for the straw. These results can be used in the optimization of millet production in agrosystems in Niger.

Keywords: Farmer Managed Natural Regeneration, Organic Manure, Mineral Fertilizer, Microdose, Combination, Millet Productivity, Niger

\section{Introduction}

Le mil est la céréale la plus cultivée au Niger (Soumana, 2001; Soler, 2008;), sur plus de 65\% de la superficie emblavée au Niger (Tougiani et al., 2013; Kadri et al., 2019). En effet, le mil domine dans les systèmes de production du pays (Hamidou et al., 2017; Kadri et al., 2019). Par ailleurs, il représente $75 \%$ de la consommation totale de céréales au Niger (FAO, 2000), assurant de ce fait la sécurité alimentaire (Saïdou, 2011) avec une dizaine de repas issues de la transformation des grains chez $85 \%$ de la population (Soumana, 2001). Les grains de cette céréale sont consommés sous forme de boule, de bouillie, de couscous, de pâte ou sous forme des galettes (Kadri et al., 2019; Hamadou et al., 2017). Cependant, cette culture est confrontée à d'énormes difficultés liées aux aléas climatiques (irrégularité spatiotemporelle de pluies) et à la pauvreté des sols (Soumana, 2001; Zakari et al., 2016). En effet, le réchauffement climatique et surtout la dégradation des propriétés physico-chimiques des sols et la croissance démographique constituent des menacent pour la production du mil (Saïdou, 2011) au Niger. Cela a entrainé pendant longtemps, l'accroissement de la production du mil à travers l'extension des superficies cultivées (Saïdou, 2011). Cette stratégie a atteint ses limites avec l'explosion de la démographie (Issaka, 2001), qui accentue la pression foncière. Cela compromet davantage la productivité du sol et la durabilité du système de culture (Saba et al., 2017). Cette situation requiert que les producteurs investissent dans l'intensification agricole (Issaka, 2001) pour améliorer leurs rendements. Alors qu'en zone semi-aride $40 \%$ de la population sont des démunis gagnant moins de 1 dollar par jour et $70 \%$ d'entre eux résident en zones rurales (JAICAF, 2009). Des études récentes (Barrett et al., 2015 ; Vanlauwe et al., 2015) ont montré qu'une faible fertilité des sols maintient les populations dans une pauvreté chronique. Aujourd'hui, pour lutter contre la paupérisation en milieu rural, l'amélioration de la fertilité des sols agricoles s'avère nécessaire. De nos jours seuls les engrais minéraux sont connus pour leurs effets immédiats et bénéfiques sur les rendements (AfricaFertilizer.org, 2012). Cependant le faible niveau de revenu 
des producteurs et l'accessibilité aux intrants agricoles limitent l'utilisation des fertilisants minéraux (Saïdou, 2011). Au Niger, l'utilisation moyenne d'engrais minéraux est d'environ $4 \mathrm{~kg} / \mathrm{ha}$ (Hamidou et al., 2014) contre 10 $\mathrm{kg} / \mathrm{ha}$ en Afrique (AfricaFertilizer.org, 2012). Ce faible apport constitue une entrave à l'amélioration de la production agricole (AfricaFertilizer.org, 2012; Saidou et al., 2014). Pour faire face à ces situations, les paysans ont adopté un certain nombre de stratégies parmi lesquelles : les techniques classiques de conservation des eaux et des sols, de défense et restauration des sols, la rotation culturale, l'association céréales-légumineuses et l'utilisation des espèces agroforestières dans les champs (Larwanou et al., 2006; Bationo et al., 2012). Dans la région de Maradi, les paysans ont adopté la pratique de la régénération naturelle assistée. Cette pratique a permis une augmentation de la fertilité de leurs sols, conduisant à des meilleurs rendements céréaliers ainsi qu'à des nouveaux moyens de subsistance alternatifs à l'agriculture (Bufflle et al., 2011). Pourtant, les rendements obtenus pour les variétés cultivées dans les champs à RNA sont toujours en deçà de la quantité prévue par la variété. Pour apporter de la valeur ajoutée à la contribution de la RNA, la combinaison RNA et engrais en microdose se présente comme une solution alternative. Cette technique consiste à faire des apports dans les champs à RNA, des quantités d'engrais minéraux et de fumure organique en microdose (FAO, 2012) dans les poquets pour améliorer davantage la fertilité des sols et la production du mil. La présente étude a pour objectif d'évaluer l'effet de la RNA combinée aux engrais, sur la production du mil. Il s'agit spécifiquement de déterminer le meilleur engrais qui permet d'apporter de la valeur ajoutée à l'effet de la RNA pour favoriser la croissance et les rendements du mil. Au Niger très peu d'études sont disponibles sur la valorisation de la RNA par les engrais. Cette étude contribuera à l'optimisation de la production du mil en assurant la sécurité alimentaire et la résilience des populations au Niger.

\section{Matériel et méthodes \\ Site d'étude}

\section{Zone sahélienne stricte}

La Commune rurale de Sherkin haoussa (Figure 1) a été choisie dans cette zone, car c'est le terroir où la pratique de la RNA est plus présente. Elle est délimitée entre $7^{\circ} 25^{\prime} 30^{\prime \prime}$ et $7^{\circ} 36^{\prime}$ de longitude Est et $13^{\circ} 46^{\prime}$ et $13^{\circ} 57^{\prime}$ de latitude Nord. Le climat est caractérisé par deux saisons, une courte saison pluvieuse de 3 à 4 mois (juin à septembre) et une longue saison sèche de 7 à 8 mois (octobre à mai). La pluviométrie moyenne annuelle est de 300 à $500 \mathrm{~mm}$. Trois types de sol sont distingués, les sols de Guéza (sols ferrugineux tropicaux), les sols de Jigawa (sols dunaires) et les sols du Goulbi de texture sablo-limoneuse (Gonda, 2009). La végétation est composée d'une steppe arbustive à trois (3) strates. Il y'a la strate herbacée constituée essentiellement 
d'espèces annuelles, la strate arbustive composée d'arbustes ligneux et la strate arborée composée d'arbres disséminés dans les champs cultivés.

\section{Zone sahélo-soudanienne}

Dans cette zone, la Commune Urbaine d'Aguié (figure 1) a été choisie, car c'est la commune de référence dans la pratique de la RNA. Elle est délimitée entre $7^{\circ} 25^{\prime} 30^{\prime \prime}$ et $7^{\circ} 36^{\prime}$ de longitude Est et $13^{\circ} 15^{\prime}$ et $13^{\circ} 36^{\prime}$ de latitude Nord. Le climat est caractérisé par deux saisons, une courte saison des pluies de juin à octobre et une longue saison sèche de novembre à mai. Les températures moyennes oscillent entre $15^{\circ} \mathrm{C}$ à $40^{\circ} \mathrm{C}$, avec une pluviométrie moyenne annuelle qui varie de 400 à $600 \mathrm{~mm}$ (Haoua, 2014). On distingue principalement deux types de sols dans la Commune, les sols dunaires (Jigawa) et les sols ferrugineux tropicaux (Guéza) de texture limoneuse. La végétation naturelle est constituée de steppe arbustive à arborée. Les ressources floristiques les plus importantes sont localisées dans les forêts classées (forêt classée de Dan Kada Dodo, forêt classée de Dan Gado, forêt classée de Bakabé).

\section{Zone nord-soudanienne}

La Commune rurale de Sarkin Yamma Saboua (figure 1) a été choisie, car elle fait partie des Communes où la RNA est plus connue dans la zone. Elle est délimitée entre $6^{\circ} 54^{\prime}$ et $7^{\circ}$ de longitude Est et $13^{\circ} 18^{\prime}$ et $13^{\circ} 30^{\prime}$ de latitude Nord. Le climat est caractérisé par une saison pluvieuse s'étalant sur 3 à 4 mois (juin à septembre) et une période sèche couvrant 8 à 9 mois (octobre à mai) par an. Les températures oscillent autour de $10^{\circ} \mathrm{C}$ à $40^{\circ} \mathrm{C}$, avec une pluviométrie moyenne annuelle qui varie entre 367,6 à $605,7 \mathrm{~mm}$. On distingue deux types de sols, les sols argileux (Fadama) situés à l'Est de la Commune et les sols dunaires ou ferrugineux tropicaux lessivés (Jigawa) situés à l'Ouest (PDC, 2011). La végétation pour l'ensemble de la Commune est structurée en trois (3) grandes unités : on observe une dominance des savanes arborées à arbustives, des steppes dans la partie nord de la Commune et des galeries forestières le long des cours d'eau. 


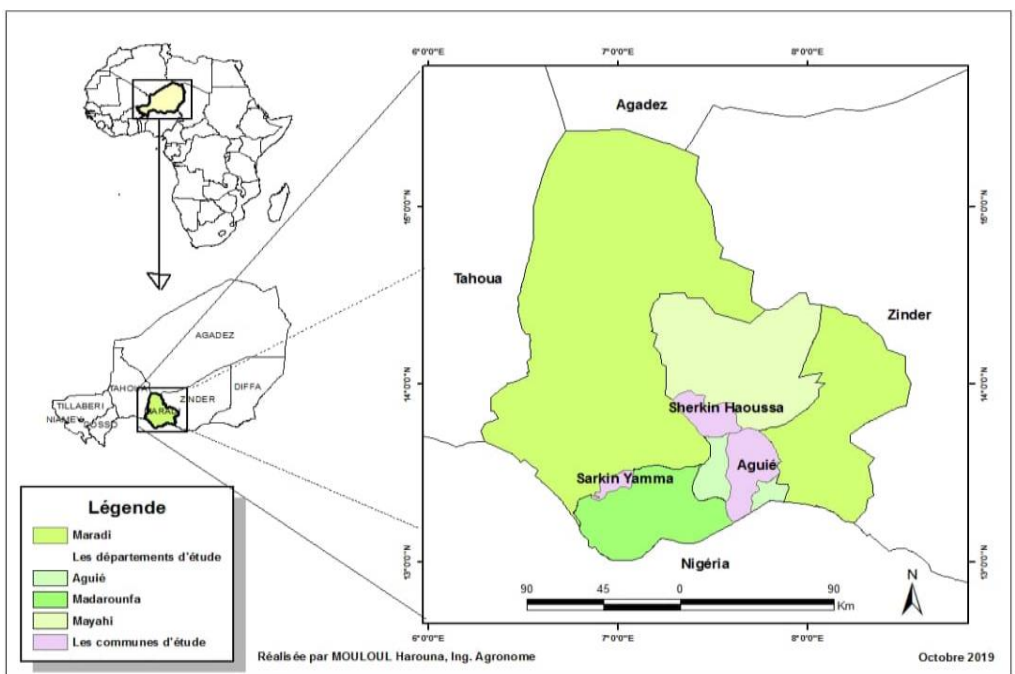

Figure 1: Carte de localisation des Communes d'étude dans la région de Maradi

\section{Matériel végétal}

Le HKP est la variété de mil (Pennicetum glaucum) améliorée obtenue par sélection pédigrée à partir de la population Hainé Kiré précoce. Cette variété de 75 à 90 jours a un rendement potentiel en grains, de 1,5 t à 2,5 t/ha. C'est une variété qui correspond aux isohyètes $350-800 \mathrm{~mm}$, obtenue à l'Institut National de la Recherche Agronomique du Niger (INRAN).

\section{Dispositif expérimental}

Les expérimentations ont été conduites en milieux paysans dans 26 villages choisis sur la base de la pratique de la RNA. Le dispositif expérimental mis en place est un bloc complet randomisé avec quatre répétitions et cinq (5) traitements avec un témoin par village. Dans chaque village, quatre (4) producteurs pratiquants la RNA ont été choisis au hasard avec l'aide du comité villageois de surveillance de la RNA. Les essais installés dans le champ de chaque producteur constituent une répétition. Les champs expérimentaux sont situés à au moins $668 \mathrm{~m}$ du village pour éviter les champs de case (Dramé et Berti, 2008) qui reçoivent plus de fertilisants. Ainsi, au niveau de chaque village un champ pour les traitements et un autre pour le témoin sont choisis suivant les quatre points cardinaux (figure 2), soit au total quatre champs pour les traitements et quatre champs témoin par village. Dans chaque champ destiné aux traitements, 5 parcelles de $200 \mathrm{~m}^{2}(20 \mathrm{~m} * 10 \mathrm{~m})$ ont été installées. Chaque parcelle reçoit après le démariage des plants de mil un des traitements suivants:

$\mathbf{R N A}=$ pratique de la régénération naturelle assistée

RNA + F= RNA + 100g de fumier par poquet de mil (soit 1t/ha) (photo 1) 
$\mathbf{R N A}+\mathbf{F}+\mathbf{N P K}=\mathrm{RNA}+100 \mathrm{~g}$ de fumier (soit $1 \mathrm{t} / \mathrm{ha})+6 \mathrm{~g}$ de NPK $(15-15-$ 15) par poquet de mil (soit $60 \mathrm{~kg} / \mathrm{ha}$ ) (photo 1 )

RNA + F + PNT $=$ RNA + $100 \mathrm{~g}$ de fumier (soit $1 \mathrm{t} / \mathrm{ha})+3 \mathrm{~g}$ de phosphate naturel de Tahoua (PNT) $(30 \mathrm{~kg} / \mathrm{ha}$ ) par poquet de mil (photo 1)

RNA + PNT $=$ RNA + 3 g de PNT par poquet de mil.

Le Témoin absolu de même dimension que ceux d'en haut, n'a reçu aucun traitement et se trouve dans un champ sans RNA.

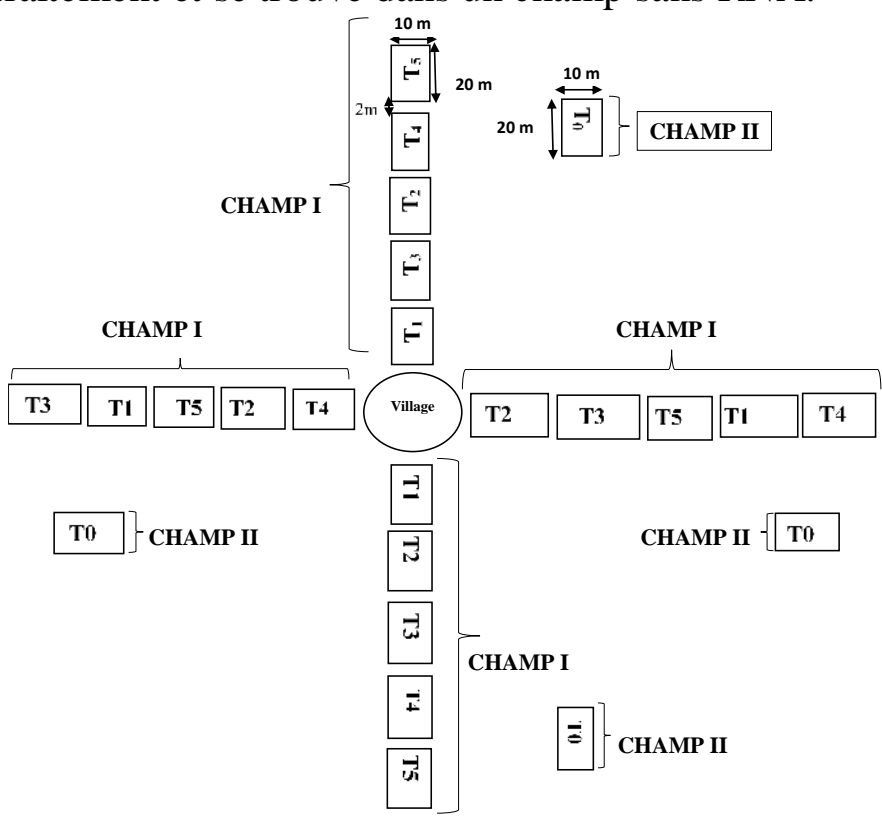

Figure 2 : Dispositif expérimental au niveau d'un village

Légende: $\mathbf{T} 0=$ Témoin, $\mathbf{T} 1=\mathrm{RNA} ; \mathbf{T} 2=\mathrm{RNA}+\mathrm{F} ; \mathbf{T} 3=\mathrm{RNA}+\mathrm{F}+\mathrm{NPK}, \mathbf{T} \mathbf{4}=\mathrm{RNA}+\mathrm{F}+\mathrm{PNT}$, T5 $=$ RNA + PNT

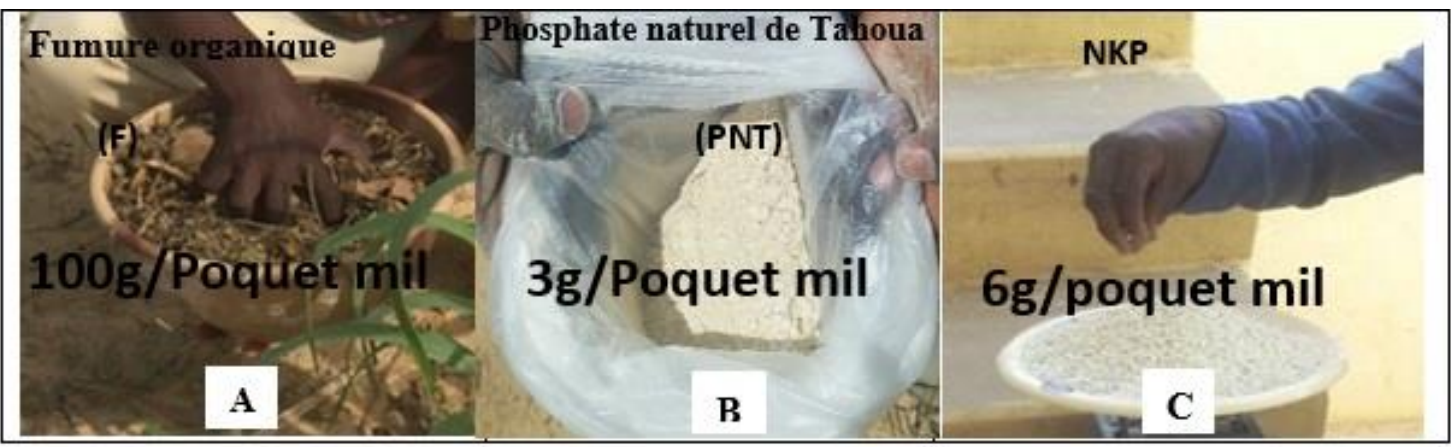

Photo 1 : fertilisants utilisés, Fumure organique (A), Phosphate naturel de Tahoua (B) et NPK $(\mathrm{C})$ 


\section{Collecte des données}

Les données ont été collectées pendant les campagnes d'hivernage 2017 et 2018 dans les trois zones d'étude (la zone sahélienne stricte, la zone sahélo-soudanienne et la zone nord-soudanienne du centre sud du Niger). Toutes les deux semaines, la hauteur du brin maître par poquet de mil a été mesurée à l'aide d'une règle graduée en planche et le nombre de talles par poquet déterminé par comptage. La récolte en grains a consisté à compter le nombre d'épis sur la parcelle expérimentale de $200 \mathrm{~m}^{2}$ et de prélever au hasard un échantillon inférieur ou égal 100 épis, selon la production d'épis par parcelle. Le rendement en paille a été déterminé à partir de 10 poquets choisis au hasard dans chaque parcelle expérimentale. La photo 2 présente un champ à RNA sous culture de mil.

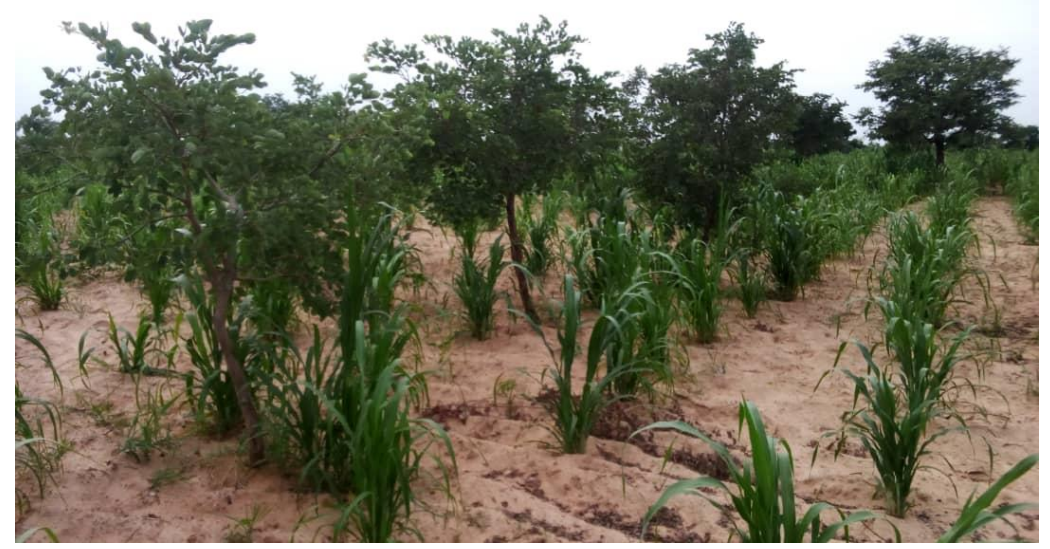

Photo 2: Vue d'un champ à RNA sous culture de mil à Garin Bajini

\section{Analyses chimiques des sols d'expérimentation}

Les échantillons de sols sont prélevés dans les champs expérimentaux suivant l'hétérogénéité de l'état de surface du sol à une profondeur de $30 \mathrm{~cm}$ avant la mise en place du dispositif. Un échantillon composite a été formé à partir des prélèvements élémentaires. Les analyses chimiques faites sur la terre fine obtenue à partir d'un tamis de maille $2 \mathrm{~mm}$, a permis de déterminer, le $\mathrm{pH}$-eau (pHmètre), le carbone organique total $(\mathrm{C})$ (Méthode de Walkey et Black), l'Azote (N) total (méthode Kjeldahl), le Phosphore total (P) (Méthode de Bray 1), le potassium total (K) (par saturation avec l'Acétate d'ammonium et lecture sur le photomètre à flamme). Ces échantillons ont été analysés au laboratoire des sols de la faculté d'agronomie de l'Université Abdou Moumouni de Niamey.

\section{Analyse et traitement des données}

Le rendement en grains de mil par parcelle a été obtenu en multipliant le nombre d'épis par le poids de l'échantillon sur le nombre d'échantillon. Et 
enfin, pour le rendement en paille par parcelle, le poids frais et sec de 10 poquets de mil choisis au hasard a été déterminé, puis évalué à l'échelle de la parcelle en connaissant le nombre de poquet récolté. Pour avoir les différents rendements à l'hectare pour chaque parcelle, une extrapolation a été faite à partir de la parcelle expérimentale.

Les données ont été saisies sur le tableur Excel puis soumises à des analyses de variance en utilisant le logiciel Minitab 16. Après la vérification de la normalité de la distribution des données, le test paramétrique ANOVA (GLM) est appliqué sur les données qui suivent une distribution normale. Dans le cas où il n'y a pas de normalité, les tests non paramétriques de KruskalWallis ou de Mann Withney ont été utilisés avec un seuil de significativité de $5 \%$. Une analyse en composante principale (ACP) a été effectuée avec le logiciel minitab 16, pour comprendre les liens entre les traitements et les différentes zones agro-écologiques.

\section{Résultats}

\section{Hauteur moyenne des plants de mil}

L'analyse de variance des hauteurs moyennes des plants de mil (figure 3) à la dernière date de mesure montrent une différence significative entre les traitements $(\mathrm{p}=0,000)$ à l'échelle de la zone d'étude. La hauteur moyenne la plus élevée est obtenue pour le traitement RNA+PNT $(274,5 \pm 72,9 \mathrm{~cm})$ et la plus faible pour le témoin $(199,6 \pm 59,8 \mathrm{~cm})$.

Dans la zone sahélienne stricte, l'analyse de variance appliquée aux dernières mesures de hauteurs montre une différence significative entre les traitements $(\mathrm{p}=0,000)$. La plus grande hauteur moyenne est obtenue pour le traitement RNA+PNT $(283,9 \pm 86,3 \mathrm{~cm})$ et la plus faible pour le témoin $(182,9 \pm 55,9 \mathrm{~cm})$.

Alors que dans la zone sahélo-soudanienne, l'analyse de variance des dernières mesures de hauteurs présente une différence significative entre les moyennes $(\mathrm{p}=0,000)$. Le traitement $\mathrm{RNA}+\mathrm{F}+\mathrm{NPK}$ obtient la hauteur moyenne la plus élevée $(268,7 \pm 24,2 \mathrm{~cm})$ et la plus faible est obtenue pour le témoin $(191,6 \pm 11,7 \mathrm{~cm})$.

Par contre, dans la zone nord-soudanienne, l'analyse de variance ne montre aucune différence significative entre les hauteurs moyennes des traitements $(\mathrm{p}=0,314)$. Néanmoins, la maximale des moyennes est obtenue pour le traitement RNA+PNT $(255,1 \pm 52,3 \mathrm{~cm})$ et la minimale pour le traitement RNA+F $(230,3 \pm 53,6 \mathrm{~cm})$. 


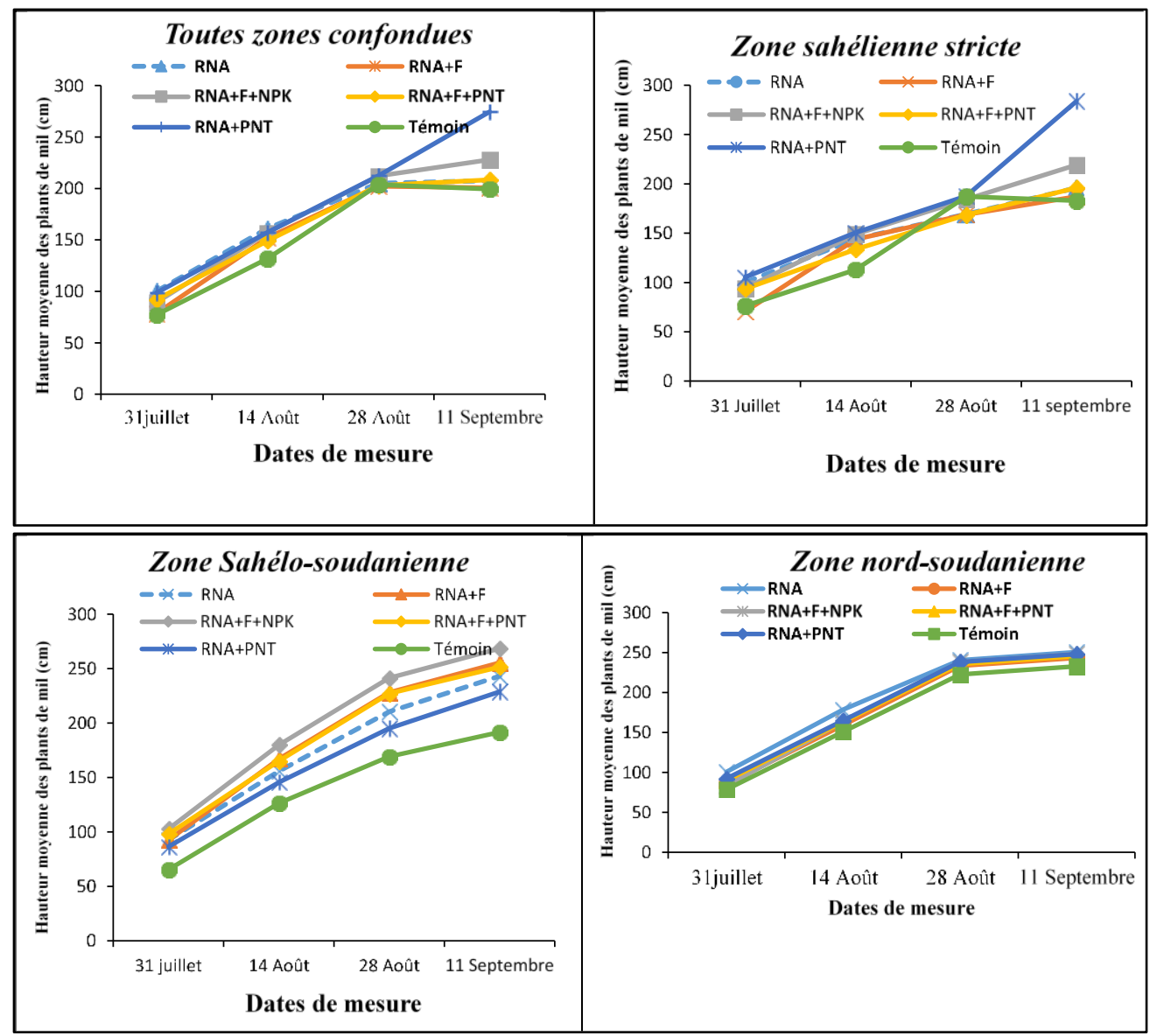

Figure 3: Hauteurs moyennes globales et par zone des plants de mil suivant chaque traitement

\section{Nombre moyen de talles par poquet de mil}

Globalement, sur l'ensemble de la zone d'étude, l'analyse de variance à la dernière date de comptage des talles montre une différence significative entre les moyennes des traitements $(\mathrm{p}=0,000)$. Le plus grand nombre moyen de talles est obtenu pour le traitement RNA+PNT $(6,9 \pm 3,4)$ et le plus faible pour le témoin $(2,8 \pm 0,6)$.

Dans la zone sahélienne stricte, l'analyse de variance montre une différence significative entre les nombres moyens des talles des traitements $(\mathrm{p}=0,000)$ pour le dernier comptage. Le plus grand nombre moyen de talles est obtenu pour le traitement RNA+PNT $(6,7 \pm 3,1)$ et le plus faible pour RNA+F $(5,4 \pm 2,1)$ et $\mathrm{RNA}+\mathrm{F}+\mathrm{PNT}(5,4 \pm 2,1)$.

Quant à la zone sahélo-soudanienne, l'analyse de variance à la dernière date de comptage montre une différence significative entre les traitements $(\mathrm{p}=0,000)$. La moyenne des talles la plus élevée est obtenue pour le traitement $\mathrm{RNA}+\mathrm{F}+\mathrm{NPK}(5,2 \pm 0,4)$ et la plus faible pour le témoin $(2,8 \pm 0,5)$. 
Enfin, dans la zone nord-soudanienne, l'analyse de variance des nombres de talles à la dernière date de comptage montre une différence significative entre les traitements $(\mathrm{p}=0,000)$. Le plus grand nombre moyen de talles est obtenu pour le témoin $(10 \pm 3,1)$ et le plus faible pour la RNA $(6,9 \pm 3,2)$.



Figure 6: Nombres moyens globaux et par zone des talles suivant chaque traitement

\section{Effet des traitements sur les rendements en grains de mil}

Les résultats des effets des traitements sur le rendement en grain de mil sont évalués dans les différentes zones. Le tableau 1 présente les rendements en grains de mil des zones d'étude.

Tableau 1: Moyennes des rendements en grains de mil par zone et par traitement

\begin{tabular}{ccccc}
\hline Traitement & $\begin{array}{c}\text { Toutes zones } \\
\text { confondues }\end{array}$ & $\begin{array}{c}\text { Zone sahélienne } \\
\text { stricte }\end{array}$ & Zone sahélo-soudanienne & $\begin{array}{c}\text { Zone nord- } \\
\text { soudanienne }\end{array}$ \\
\hline RNA & $314,6 \pm 194,9^{\mathrm{ac}}$ & $240,8 \pm 135,7^{\mathrm{a}}$ & $347,8 \pm 219,2^{\mathrm{ac}}$ & $377,9 \pm 200,1^{\mathrm{a}}$ \\
RNA+F & $343,1 \pm 203,3^{\mathrm{ac}}$ & $276,7 \pm 161^{\mathrm{a}}$ & $369,8 \pm 204,7^{\mathrm{ac}}$ & $405,4 \pm 237,2^{\mathrm{a}}$ \\
RNA+F+NPK & $410,6 \pm 232,1^{\mathrm{ab}}$ & $324,8 \pm 212,3^{\mathrm{a}}$ & $464,1 \pm 213,9^{\mathrm{ab}}$ & $457,7 \pm 258,6^{\mathrm{a}}$ \\
RNA+F+PNT & $354 \pm 210,8^{\mathrm{a}}$ & $255,3 \pm 161^{\mathrm{a}}$ & $398,8 \pm 202,4^{\mathrm{a}}$ & $437,5 \pm 239,5^{\mathrm{a}}$ \\
RNA+PNT & $329,7 \pm 198^{\mathrm{ac}}$ & $245,5 \pm 155,8^{\mathrm{a}}$ & $374,2 \pm 195,8 \mathrm{ac}$ & $390,2 \pm 221,7^{\mathrm{a}}$ \\
Témoin & $197,6 \pm 129,5^{\mathrm{b}}$ & $133,3 \pm 122,7^{\mathrm{b}}$ & $170,9 \pm 92^{\mathrm{b}}$ & $285,2 \pm 147,3^{\mathrm{a}}$ \\
\hline Probabilité & $\mathbf{0 , 0 0 0}$ & $\mathbf{0 , 0 0 0}$ & $\mathbf{0 , 0 0 0}$ & $\mathbf{0 , 0 6 0}$ \\
\hline
\end{tabular}

"Les mêmes lettres dans une colonne signifient qu'il n'y a pas de différence entre les moyennes, les lettres différentes signifient qu'il y'a une différence entre les moyennes" au seuil de $5 \%$

L'analyse de variance montre qu'il y'a une différence significative entre les rendements moyens en grains des traitements pour toutes les zones confondues 
( $\mathrm{p}<0,05)$. Le rendement le plus élevé est obtenu pour le traitement RNA+F+NPK $(410,6 \pm 232,1 \mathrm{~kg} / \mathrm{ha})$ et le plus faible pour le témoin $(197,6 \pm 129,5 \mathrm{~kg} / \mathrm{ha})$.

Alors que dans la zone sahélienne stricte, les moyennes des rendements en grains pour les traitements RNA; RNA+F ; RNA+F+NPK ; $\mathrm{RNA}+\mathrm{F}+\mathrm{PNT}$ et RNA+PNT ne sont pas significativement différents entre eux ( $>0,05)$. Ces traitements présentent une différence significative par rapport au témoin $(\mathrm{p}<0,05)$. Le traitement RNA+F+NPK $(324,8 \pm 212,3 \mathrm{~kg} / \mathrm{ha})$ obtient le rendement moyen le plus élevé de la zone.

Dans la zone sahélo-soudanienne, la moyenne du traitement $\mathrm{RNA}+\mathrm{F}+\mathrm{NPK}$ présente une différence significative avec les autres traitements sauf RNA+F+PNT. Quant à la moyenne du témoin, elle est significativement différente que tous les autres traitements $(\mathrm{p}<0,05)$. La moyenne la plus élevée est obtenue pour le traitement RNA+F+NPK $(464,1 \pm 213,9 \mathrm{~kg} / \mathrm{ha})$.

Par contre, en zone nord-soudanienne aucune différence significative n'a été observée entre les traitements $(\mathrm{p}>0,05)$, Néanmoins, le rendement le plus élevé est obtenu pour le traitement RNA+F+NPK $(457,7 \pm 258,6 \mathrm{~kg} / \mathrm{ha})$.

\section{Effet des traitements sur les rendements en paille de mil}

Une analyse de variance est réalisée pour comprendre l'effet des traitements sur les rendements en paille de mil. Les résultats des analyses sont consignés dans le tableau 2.

Tableau 2: Moyennes des rendements en paille de mil par zone et par traitement

\begin{tabular}{ccccc}
\hline Traitement & $\begin{array}{c}\text { Toutes zones } \\
\text { confondues }\end{array}$ & $\begin{array}{c}\text { Zone sahélienne } \\
\text { stricte }\end{array}$ & $\begin{array}{c}\text { Zone sahélo- } \\
\text { soudanienne }\end{array}$ & $\begin{array}{c}\text { Zone nord- } \\
\text { soudanienne }\end{array}$ \\
\hline RNA & $1522,7 \pm 736,6^{\mathrm{a}}$ & $1100,8 \pm 547,6^{\mathrm{a}}$ & $1802 \pm 812^{\mathrm{a}}$ & $1727 \pm 540^{\mathrm{a}}$ \\
RNA+F & $1615,9 \pm 827,1^{\mathrm{a}}$ & $1199,6 \pm 579,7^{\mathrm{a}}$ & $1947 \pm 954^{\mathrm{a}}$ & $1720 \pm 638^{\mathrm{a}}$ \\
$\mathbf{R N A + F + N P K}$ & $1754,2 \pm 959,9^{\mathrm{a}}$ & $1230,6 \pm 553,6^{\mathrm{a}}$ & $2126 \pm 1193^{\mathrm{a}}$ & $1964 \pm 599 \mathrm{a}$ \\
RNA+F+PNT & $1625,2 \pm 849,8^{\mathrm{a}}$ & $1124,6 \pm 525,3^{\mathrm{a}}$ & $1973 \pm 1016^{\mathrm{a}}$ & $1838,4 \pm 525,4^{\mathrm{a}}$ \\
RNA+PNT & $1554,9 \pm 899,4^{\mathrm{a}}$ & $1095,2 \pm 563,7^{\mathrm{a}}$ & $1910 \pm 1120^{\mathrm{a}}$ & $1689 \pm 536^{\mathrm{a}}$ \\
Témoin & $516 \pm 462,9^{\mathrm{b}}$ & $238,5 \pm 238,2^{\mathrm{b}}$ & $802,4 \pm 401,6^{\mathrm{b}}$ & $427,2 \pm 519^{\mathrm{b}}$ \\
\hline Probabilité & $\mathbf{0 , 0 0 0}$ & $\mathbf{0 , 0 0 0}$ & $\mathbf{0 , 0 0 0}$ & $\mathbf{0 , 0 0 0}$ \\
\hline
\end{tabular}

"Les mêmes lettres dans une colonne signifient qu'il n'y a pas de différence entre les moyennes, les lettres différentes signifient qu'il y'a une différence entre les moyennes" au seuil de $5 \%$

L'analyse de variance entre les rendements moyens en paille de mil montre que sur l'ensemble de la zone d'étude et dans les zones agro-écologiques, il n'y a pas de différence significative entre les traitements RNA, RNA+F, $\mathrm{RNA}+\mathrm{F}+\mathrm{NPK}, \mathrm{RNA}+\mathrm{F}+\mathrm{PNT}$ et RNA+PNT ( $>0,05)$. Mais, ces derniers sont significativement différents du témoin $(\mathrm{p}<0,05)$. Pour toutes les zones confondues et par zone agro-écologique, le traitement $\mathrm{RNA}+\mathrm{F}+\mathrm{NPK}$ possède 
les rendements les plus élevés en paille de mil $(1230,6 \pm 553,6$ à $2126 \pm 1193$ $\mathrm{kg} / \mathrm{ha})$.

\section{Relations entre la production du mil par traitement et les zones agro- écologiques}

Les données sur les rendements moyens en grains et en pailles de mil et les zones agro-écologiques ont été soumises à une analyse en composante principale (ACP). Les deux premiers axes concentrent à eux seuls $100 \%$ de la variance totale (figure 7). L'axe 1 concentre à lui seul $88,9 \%$ et l'axe 2 à $11,1 \%$. L'analyse du plan factoriel montre que la zone sahélo-soudanienne et nord-soudanienne favorisent mieux les rendements moyens en grains et en pailles de mil. Spécifiquement, les champs témoins de la zone sahélosoudanienne sont beaucoup plus favorables à la production de pailles de mil et celles de la zone nord-soudanienne en grains de mil.

\section{Diagramme en double projection (100\%)}

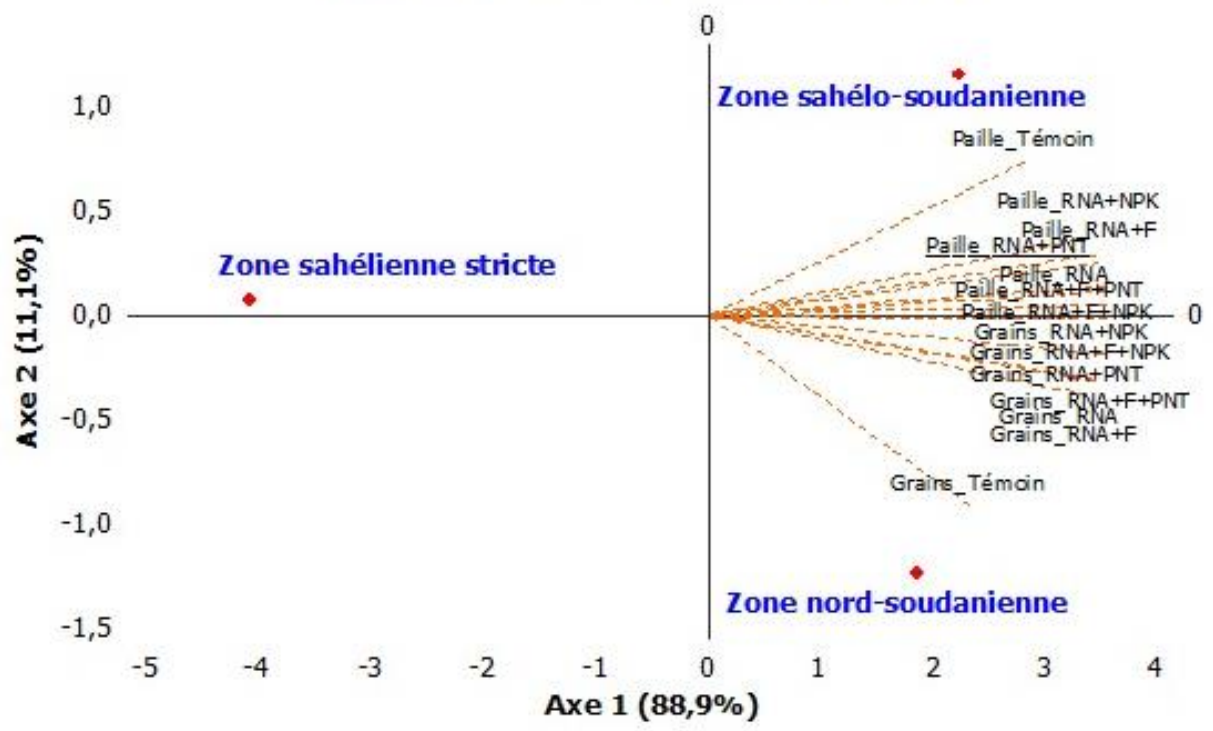

Figure 7: Relation entre les rendements moyens en grains et en pailles de mil par traitement et les zones agro-écologiques

\section{Analyses chimiques des sols expérimentaux}

La teneur des sols en éléments chimiques nécessaires au bon développement des plantes est analysée dans les trois zones. Le tableau 3 donne les résultats des différentes analyses effectuées. 
Tableau 3: Résultats des tests de comparaison des valeurs de $\mathrm{pH}$, de carbone, d'azote, de phosphore total, de potassium et le rapport $\mathrm{C} / \mathrm{N}$ entre les zones.

\begin{tabular}{lllll}
\hline $\begin{array}{l}\text { Paramètre } \\
\text { chimique }\end{array}$ & $\begin{array}{l}\text { Zone } \\
\text { stricte }\end{array}$ & $\begin{array}{l}\text { sahélienne } \\
\text { Zone } \\
\text { soudanienne }\end{array}$ & $\begin{array}{l}\text { sahélo- } \\
\text { Zone } \\
\text { soudanienne }\end{array}$ & Nord- Probabilité \\
\hline pHeau & $5,77 \pm 0,16^{\mathrm{a}}$ & $5,88 \pm 0,27^{\mathrm{a}}$ & $5,68 \pm 0,31^{\mathrm{a}}$ & 0,115 \\
$\mathbf{C \%}$ & $0,216 \pm 0,072^{\mathrm{ac}}$ & $0,2907 \pm 0,086^{\mathrm{ab}}$ & $0,2607 \pm 0,069^{\mathrm{a}}$ & $<0,033$ \\
$\mathbf{N \%}$ & $0,018 \pm 0,004^{\mathrm{a}}$ & $0,02933 \pm 0,01^{\mathrm{a}}$ & $0,02733 \pm 0,011^{\mathrm{a}}$ & 0,075 \\
$\mathbf{P T p p m}$ & $14,82 \pm 5,5^{\mathrm{a}}$ & $20,42 \pm 4,43^{\mathrm{b}}$ & $14,418 \pm 1,927^{\mathrm{a}}$ & $<0,000$ \\
K méq/100g & $0,07 \pm 0,02^{\mathrm{b}}$ & $0,10333 \pm 0,017^{\mathrm{a}}$ & $0,08267 \pm 0,025^{\mathrm{b}}$ & $<0,000$ \\
C/N & $10,14 \pm 1,035^{\mathrm{a}}$ & $10,208 \pm 1,173^{\mathrm{a}}$ & $10,315 \pm 2,157^{\mathrm{a}}$ & 0,293 \\
\hline
\end{tabular}

"Les mêmes lettres dans une ligne signifient qu'il n'y a pas de différence entre les moyennes, les lettres différentes signifient qu'il y'a une différence entre les moyennes" au seuil de 5\%

L'analyse de variance montre une différence significative pour les teneurs en $\mathrm{C}$, $\mathrm{P}$ et $\mathrm{K}(\mathrm{p}<0,05)$ entre les zones agro-écologiques. La zone sahélo-soudanienne obtient les valeurs les plus élevées suivis de la zone nordsoudanienne pour le $\mathrm{C}$ et $\mathrm{K}$. Alors que pour le $\mathrm{P}$, après la zone sahélosoudanienne, c'est la zone sahélienne stricte qui obtient la plus grande valeur. Quant au $\mathrm{pH}$, la teneur en $\mathrm{N}$ et le rapport $\mathrm{C} / \mathrm{N}$, aucune différence significative n'a été obtenue entre les zones. Néanmoins, les valeurs les plus élevées pour le $\mathrm{pH}$ et $\mathrm{N}$ sont obtenues dans la zone sahélo-soudanienne et le plus grand rapport $\mathrm{C} / \mathrm{N}$ dans la zone nord-soudanienne.

\section{Discussion}

\section{Hauteur et nombre de talles de mil}

A la dernière mesure de hauteurs des plants de mil, le traitement RNA+PNT a permis d'obtenir la hauteur moyenne de plants élevée dans la zone sahélienne stricte $(283,9 \pm 86,2 \mathrm{~cm})$. Dans les sols de cette zone le traitement RNA+ PNT favorisent mieux la croissance en hauteur des plants de mil. Cela est due aussi bien aux caractéristiques chimiques des sols qui sont favorables (Dan Lamso et al, 2015a) dans cette zone influencée par la pratique de la RNA (Ibrahima, 2011; Traoré, 2009; Mansour et al., 2013; Dan Lamso et al, 2015b; Camara et al., 2017), qu'aux éléments fertilisants apportés par les engrais. Ces résultats corroborent aussi ceux obtenus par Hamidou et al. (2016) qui rapporte qu'au Sahel les sols sont très pauvres en phosphore, alors que le phosphore permet d'augmenter la croissance de la tige de mil de $153 \%$. La carence en phosphore dans la majorité des sols nigériens a été rapportée aussi par RECA (2012), qui affirme que parmi les facteurs militants, d'ordre chimique, la carence en phosphore $(\mathrm{P})$ est l'une des plus graves.

Le nombre moyen de talles par poquet de mil le plus élevé des zones est obtenu pour le témoin de la zone nord-soudanienne (10,04 \pm 3$)$. Ce dernier est peut-être influencé par la biomasse des espèces ligneuses apportées par le vent, ou bien par les apports antérieurs d'engrais sur les précédentes cultures. 
Ces chiffres sont supérieurs à ceux obtenus par Dutordoir (2006) qui a obtenus des nombres de talles moyens de 3,34 pour le DAP et 3,25 pour le DAP +Urée dans le Fakara à l'ouest du Niger. Cette différence peut être liée aux variétés, à la pratique de la RNA et aux conditions pédoclimatiques des zones d'études.

\section{Évolution du rendement de mil}

Le traitement RNA+F+NPK a permis d'obtenir aussi bien les rendements moyens en grains les plus élevés qu'en pailles de mil, dans toutes les zones, avec les quantités les plus élevées dans la zone sahélo-soudanienne $(464,1 \pm 213,9 \mathrm{~kg} / \mathrm{ha}$ pour les grains et $2126 \pm 1193 \mathrm{~kg} / \mathrm{ha}$ pour les pailles). Cela est relatif à la pratique de la RNA, c'est-à-dire non seulement à la diversité d'espèces ligneuse présentes, mais aussi à l'ancrage de la pratique (Assama, 2004). Il y'a aussi le niveau de protection et de gestion de la RNA, ainsi que les conditions climatiques qui sont moyennement favorables dans la zone sahélo-soudanienne (Zounon et al., 2019). Dans cette zone la RNA est plus pratiquée avec une richesse spécifique d'espèces plus élevée (Zounon et al., 2019). Ceci implique un renforcement régulier du stock de matière organique du sol, à travers l'apport de biomasse végétale variée qui renforce plus le stock de fertilisants du sol. Ces résultats corroborent ceux obtenus par Boubé (2008) qui rapport que les rendements en grains augmentent si la densité des arbres croit. Selon Gonda (2009) et Kagne (2012) aussi, la RNA contribue à l'amélioration de la fertilité des sols à travers l'augmentation de l'humus du sol par la production de biomasse. Celle-ci libérée par la RNA associée au fumier et à la bonne pluviométrie des années d'expérimentation ont favorisé une bonne absorption des engrais minéraux par les cultures. Ces résultats sont en accord avec ceux obtenus par Hamidou et al. (2014) qui rapporte que la combinaison des engrais organiques et minéraux permet d'accroître durablement la production agricole. Et selon, Dutordoir (2006) l'utilisation d'engrais minéraux, couplée à l'application d'engrais organiques est la solution phare pour satisfaire la demande alimentaire croissante sans aggraver la dépendance du pays vis-à-vis de l'aide internationale. La zone sahélosoudanienne possédant les plus grands rendement en grains et en pailles de mil est caractérisée par C. glutinosum comme espèce importante (Zounon et al., 2019). Alors que la zones nord-soudanienne et sahélienne stricte possédant $P$. reticulatum comme espèce importantes (Zounon et al., 2019) sont caractérisées par des faibles rendements . Ceci permettrait de dire que la richesse en éléments minéraux de la biomasse de $C$. glutinosum peut être responsable de cette dominance. Car, il a été rapporté par Fati (2007) que selon les pratiquants de la RNA de la zone sahélo-soudanienne l'espèce $C$. glutinosum fertilise plus le sol après Faidherbia albida. Les faibles rendements obtenus dans les zones dominées par $P$. reticulatum peuvent-être dus au fait que c'est une espèce appétée par les animaux. Cette fonction qu'elle 
assure peut réduire l'apport de sa biomasse dans l'amélioration de la fertilité des sols. Le rendement moyen en grains obtenu en zone sahélo-soudanienne $(464,1 \pm 213,9 \mathrm{~kg} / \mathrm{ha})$ est supérieur à ceux obtenus au niveau régional et national qui étaient respectivement de $393 \mathrm{~kg} / \mathrm{ha}$ et $418 \mathrm{~kg} / \mathrm{ha}$ (INS, 2014). Ce résultat est inférieur à ceux obtenus par Dan Lamso et al. (2015b) qui étaient de 1300 à $1820 \mathrm{~kg} / \mathrm{ha}$ autour des touffes de Hyphaene thebaica. Ils sont aussi inférieurs à ceux obtenus par Dutordoir (2006) avec des rendements de 654 $\mathrm{kg} / \mathrm{ha}$ pour le DAP et $665 \mathrm{~kg} /$ ha pour le DAP + Urée dans le Fakara au Niger. Mais, ils sont supérieurs à ceux obtenus par Assama (2004) dans la zone sahélo-soudanienne qui varient de $175 \mathrm{~kg} / \mathrm{ha}$ à $370 \mathrm{~kg} / \mathrm{ha}$. Le rendement en paille de mil obtenu dans la zone sahélo-soudanienne $(2126 \pm 1193 \mathrm{~kg} / \mathrm{ha})$ est supérieur à ceux obtenus par Dutordoir (2006) pour le traitement DAP (1323 $\mathrm{kg} / \mathrm{ha}$ ) et DAP + Urée (1369 kg/ha). Ces variations peuvent-être liées aussi bien aux zones d'expérimentation qu'aux variétés de mil et à la pratique de la RNA.

\section{Paramètres chimiques des sols expérimentaux}

La dominance significative de $\mathrm{C}$, $\mathrm{P}$ et $\mathrm{K}$ dans les sols de la zone sahélosoudanienne ont contribué à obtenir des rendements plus élevés en grains et en paille de mil pour le traitement $\mathrm{RNA}+\mathrm{F}+\mathrm{NPK}$ dans cette zone. Les éléments $\mathrm{C}, \mathrm{P}$ et $\mathrm{K}$ qui dominent dans la zone sahélo-soudanienne peut être due à la qualité de la biomasse apportée par les espèces ligneuses de la RNA au sol. Les résultats obtenus sur l'ensemble des zones montrent que les teneurs en $\mathrm{C}$ $(0,216 \pm 0,072$ à $0,2907 \pm 0,086 \mathrm{ppm}), \mathrm{N}(0,018 \pm 0,004$ à $0,02933 \pm 0,01 \%)$ et $\mathrm{K}$ $(0,07 \pm 0,02$ à $0,10333 \pm 0,017$ méq/100g) sont supérieurs à ceux obtenues par Issaka (2001) sur les sols jigawa à une profondeur de 5 à $20 \mathrm{~cm}$ dans la région d'étude $(\mathrm{C}=.0,06$ à $0,07 \% ; \mathrm{N}=0,02$ à $0,023 \% ; \mathrm{K}=0,03$ à 0,04 méq/100g). Un $\mathrm{pH}$ de $5,68 \pm 0,31$ à $5,88 \pm 0,27$ obtenu est à peu près égal à 5,5 à 6 obtenu par Issaka (2001) dans la même région. Cette différence peut s'expliquer par le fait que le choix des zones d'études de Issaka (2001) n'est pas conditionné par la pratique de la RNA. Alors que la teneur en phosphore total $(14,418 \pm 1,927 a ̀$ 20,42 44,43) est inférieure à celle obtenue par Dan Lamso et al. (2015b) qui est de $105,58 \mathrm{ppm}$ à $0 \mathrm{~cm}$ et $101,79 \mathrm{ppm}$ à $50 \mathrm{~cm}$ de profondeur du sol dans la même région. Cela est due au fait que Dan Lamso et al. (2015b) ont prélevé leurs échantillons de sols autours des touffes d'Hyphaene thebaica qui est une espèce végétale riche en phosphore.

\section{Conclusion}

Il ressort de cette étude que la pratique de la RNA à elle seule contribue favorablement à la fertilisation des sols et à l'amélioration de la production du mil. Cette contribution s'effectue entre autres à travers un apport important de biomasse végétale qui varie d'une zone à une autre, cela est relative à la 
pratique de la RNA. Cette pratique associée à l'apport en microdose des engrais a permis d'améliorer la fertilité des sols et d'optimiser la production du mil. Le traitement RNA+F+NPK s'est avéré le plus efficace sur la productivité du mil, bien que le traitement RNA+PNT ait aussi été efficace dans la croissance du mil en zone sahélienne stricte. Globalement, les traitements du mil sont beaucoup plus favorisés dans les zones sahélosoudanienne en raison de l'ancrage de la pratique de la RNA. A cela s'ajoute les conditions pédoclimatiques et l'attention accordée par la population et les services techniques, accompagnés par leurs partenaires au développement. Les rendements du mil peuvent-être améliorés en ciblant la bonne période de réduction du houppier des espèces ligneuses de la RNA. Afin d'éviter la compétition entre les plants du mil et les espèces ligneuses dans la recherche de la lumière.

\section{Remerciement}

A l'Institut international de recherche sur les cultures des zones tropicales semi-arides (ICRISAT/ Niamey) pour son appui financier dans la réalisation de ce travail.

\section{References:}

1. AfricaFertilizer.org., 2012. Manuel de Formation Statistiques sur les Engrais en Afrique 114p.

2. Assama S., 2004. Valorisation des produits et sous-produits ligneux dans la partie nord d'Aguie «cas du terroir villageois de dan- saga», Mémoire de fin d'études, Ingénieur des techniques agricoles, Option Eaux et Forêts, Faculté d'agronomie, Université Abdou Moumouni de Niamey, 84p.

3. Barrett C B. et Bevis L E M., 2015. The self-reinforcing feedback between low soil fertility and chronic poverty, Nature Geoscience 8: 907-912.

4. Bationo B A., Kalinganiré A. et Bayala J., 2012. Potentialités des ligneux dans la pratique de l'agriculture de conservation dans les zones arides et semi arides de l'Afrique de l'Ouest : Aperçu de quelques systèmes candidats ; ICRAF Technical Manual no. 17 Nairobi : World Agroforestry Centre 32P.

5. Bufflle P., Reij C. et Guadagno L., 2011. Building Resilience to Climate Change through Farmer managed Natural Regeneration in Niger and Land Rehabilitation in Burkina Faso. Elan, Ecosystems Livelihoods. Adaptation Network, 13 p.

6. Boube R., 2008. Impacts de la Régénération Naturelle Assistée des ligneux sur la production du Mil et du Niébé danas le Département d'Aguié : Cas du Terroir villageois de Guidan Bakoye , Rapport de 
stage pour l'obtention du diplôme de Maitrise ès sciences agronomiques , Faculté d'Agronomie, Université de Niamey, 39 pages.

7. Camara B A., Drame M, Sanogo D, Ngom D, Badji M. et Diop M., 2017. La régénération naturelle assistée : perceptions paysannes et effets agro-écologiques sur le rendementdu mil (Pennisetum glaucum (L.) R. Br.) dans le bassin arachidier au Sénégal, Journal of Applied Biosciences 112: 11025-11034, ISSN 1997-5902

8. Dan Lamso N., guero Y., Tankari Dan-Badjo A., Lamar R., Andre Bationo B., Djamen P., Tidjani A D., Ado Maman N. et Ambouta JMK., 2015a. Effet des touffes de Hyphaene thebaica (Mart) sur la production du mil dans la région de Maradi (Niger), Int. J. Biol. Chem. Sci. 9(5) : 2477-2487, October 2015.

9. Dan Lamso N, Guero Y., Tankari D-B A., Rabah L., Andre B B., Patrice D., Tidjani A D., Ado M N. et Ambouta J-M K., 2015 b. Variations texturales et chimiques autour des touffes d'hyphaene thebaica (mart) des sols dans la region de Maradi (Niger), Algerian journal of arid environment, vol. 5, $\mathrm{n}^{\circ}$ 1, Juin 2015: 40-55.

10. Dramé Y A. et Berti F., 2008. Les enjeux socioéconomiques autour de l'agroforesterie villageoise à Aguié (Niger). Tropicultura, 26 (3): 141149.

11. Dutordoir D C., 2006.Impact de pratiques de gestion de la fertilité sur les rendements en mil dans le Fakara (Niger); Faculté d'ingénierie biologique, agronomique et environnementale; université catholique de Louvain; 161p.

12. FAO., 2000. Production yearbook. Food and Agricultural Organization, Rome. Alimentation et agriculture. Production et santé animales par J.W. Czerkawski, J.D. Dargie, L. E. Edqvist, M.C.N. Jayasuriya. FAO.

13. FAO., 2012. Capitalisation des bonnes pratiques en appui à la production alimentaire et à la sécurité alimentaire ; fiche d'information, Niger, $4 \mathrm{p}$.

14. Fati B., 2007. Impact de la RNA sur la fertilité du sol : cas du terroir de Guidan Bakoye (Aguie);Mémoire de fin d'étude ; ITA; Eaux et Forêts; Faculté d'Agronomie de l'Université Abdou Moumouni de Niamey 38p.

15. Gonda A., 2009. Influence des conditions socio-économiques et culturelles sur la dynamique des écosystèmes sahéliens: Cas de zones reverdie (Warzou) et dégradée (Maïssakoni) du département de Mayahi; Université Abdou Moumouni; Faculté d'Agronomie; Centre Régional d'Enseignement Spécialisé en Agriculture de Niamey; Centre 
d'Excellence Régional de l'UEMOA (CRESA - CER / UEMOA); DESS; $56 \mathrm{p}$.

16. Hamadou M., Idrissa S., Mahamadou C., Oumarou S. et Valentin K., 2017. Potentialités fourragères du mil (Pennisetum glaucum (L.) R. Br) : Revue de littérature. Journal of Animal \& Plant Sciences, 34(2): 5424-5447.

17. Hamidou Z., Mahamane S., Bismarck N H., Bado B V., Lompo F. et Bationo A., 2014. Effet de la combinaison des fumures organominérales et de la rotation niébé-mil sur la nutrition azotée et les rendements du mil au sahel, Int. J. Biol. Chem. Sci. 8(4): 1620-1632, August 2014.

18. Hamidou Z., Mahamane S., Payne W A., Sedogo M., Lompo F. et Bismarck N H., 2016. Impact des modes de gestion de la fertilité du sol et des systèmes de production sur la nutrition azoté et les rendements du mil (Pennicetum glaucum (L.) R.Br) au Niger, TROPICULTURA, 2016, 34,4 335-348.

19. Haoua I O., 2014. Evaluation des ressources forestières et leur mode de gestion dans le terroir de dan saga (Aguie, Niger), mémoire master en gestion des ressources naturelles et de la biodiversité, RESBIO, $71 \mathrm{p}$.

20. Ibrahima A., Mvondo ze A D. et Ntonga J C., 2011. Litter decomposition and nutrient dynamics of ten selected tree species in tropical rainforest of Ebom, southwest Cameroon, Int. J. Biol. Chem. Sci. 5(1): 11-27.

21. INS., 2014. Institut national de la statistique, annuaire statistique 20092013; 245 p.

22. Issaka M., 2001. Evolution à long terme de la fertilité de sol dans la région de Maradi. Drylands Research Crewkerne, Somerset, Royaume-Uni. Working Paper 30.36p

23. JAICAF., 2009. Les céréales au Niger, accent sur le mil et le sorgho, L'Association pour la Collaboration Internationale en matière d'Agriculture et de Forêts du Japon, 109p.

24. Kadri A., Halilou H. et Karimou I., 2019. Culture du mil [Pennisetum glaucum $(\mathrm{L}) \mathrm{R}$. Br] et ses contraintes à la production: une revue, Int. J. Biol. Chem. Sci. 13(1): 503-524

25. Kagne F., 2012. Impact socio-économique de la régénération naturelle assistée (RNA) dans les stratégies d'améliorations des moyens de subsistance des producteurs agricoles: cas de la Gnagna et du Gourma, Diplôme d'ingénierie du développement rural, Sociologie et économie Rurales, Université Polytechnique de Bobo-Dioulasso, Burkina Faso, $80 \mathrm{p}$. 
26. Larwanou M., Abdoulaye M. et Chris R., 2006. Etude de la Régénération Naturelle Assistée dans la région de Zinder (Niger) ; une première exploitation d'un phénomène spectaculaire. USAID/IRGFRAME, 56 p.

27. Mansour AM., Zoubeirou A M., Kadri A., Ambouta J-M K. et Dan Lamso N., 2013. Effet de l'arbre Acacia senegal sur la fertilité des sols de gommeraies au Niger. Int. J. Biol. Chem. Sci., 7(6): 2328-2337.

28. PDC (Plan de Développement Communal)., 2011. Rapport de Commune Rurale de Serkin Yamma, 52p.

29. RECA., 2012. Phosphate / la recherche insiste depuis 40 ans sur ce facteur limitant des cultures pluviales Investir dans la «bonification » des terres, Réseau National des Chambres d'Agriculture du Niger, Note d'information / Intrants $n^{\circ} 20,5 p$

30. Saïdou A., 2011. Etude moléculaire, évolution et caractérisation de gènes impliqués dans l'adaptation du mil [Pennisetum glaucum (L.) R. $\mathrm{Br}$.] aux changements climatiques. Thèse de doctorat, Montpellier SupAgro, Montpellier, 236 p.

31. Saidou A K; Sabiou M., Maman G., Oumarou I., Ibrahima M G. et Ambouta J-M K., 2014. Effet d'enrobage des graines et de la microdose des engrains sur des variétés du mil en zone semi-arides du Niger, Rapport d'étude de l'INRAN en collaboration avec l'UAM et AGRA, 12p.

32. Saba F, Taonda S J B., Serme I., Bandaogo A A., Sourwema A P. et Kabre A., 2017. Effets de la microdose sur la production du niébé, du mil et du sorgho en fonction la toposéquence, Int. J. Biol. Chem. Sci. 11(5): 2082-2092, October 2017.

33. Soler C M T., Maman N., Zhang X., Mason S C. et Hoogenboom G., 2008. Determining optimum planting dates for pearl millet for two contrasting environments using a modelling approach. Journal of Agricultural Science, 146: 445-459.

34. Soumana I., 2001. Bilan diagnostic sur la production du mil et du Sorgho au Niger. Initiative pour le développement des mils et sorghos en Afrique de l'Ouest et du Centre, un pilotage par l'aval, Cadre national de concertation, $96 \mathrm{p}$.

35. Tougiani A., Yayé A., Aboul Habou Z., Adamou A I. et Adam T., 2013. Influence des Parcs agro-forestiers à Piliostigma reticulatum sur l'infestation des plants de mil par les insectes floricoles et Coniesta ignefusalis (Hmps) (Lépidoptère: Pyralidae) dans la zone d'Aguié au Niger. Journal of Applied Biosciences, 66: 5140-5146.

36. Traoré B., 2009. Effets des techniques de gestion de la fertilité sur le sol et sur les systèmes de culture à base de mil dans la région de Mopti au Mali, Thèse de Doctorat, Option : Ecologie Appliquée, à 
l'Université de Bamako, Faculté des sciences et techniques, D. E. R. de Biologie.

37. Vanlauwe B., Six J., Sanginga N. et Adesina A A., 2015. Soil fertility decline at the base of rural poverty in sub-Saharan Africa. Nature Plants, 1: 15101.

38. Zakari A H., Mahamadou B. et Adam T., 2016. Les systèmes de productions agricoles du Niger face au changement climatique : défis et perspectives. Int. J. Biol. Chem. Sci., 10(3): 1262-1272.

39. Zounon C S F., Abasse T., Massaoudou M., Habou R., Addam k. et Ambouta K., 2019. Diversité Et Structure Des Peuplements Ligneux Issus De La Régénération Naturelle Assistée (RNA) Suivant Un Gradient Agro-Ecologique Au Centre Sud Du Niger.” IOSR Journal of Agriculture and Veterinary Science (IOSR-JAVS) 12.1 (2019): PP$52-62$. 